\title{
The Effects of Nalbuphine and Butorphanol Treatment on Cocaine and Food Self-Administration by Rhesus Monkeys
}

Nancy K. Mello, Ph.D., Jonathan B. Kamien, Ph.D.1, Scott E. Lukas, Ph.D., John Drieze, M.S., and Jack H. Mendelson, M.D.

This study was designed to determine whether opioid mixed agonist-antagonist analgesics other than buprenorphine also selectively reduce cocaine selfadministration by rhesus monkeys. The effects of daily treatment with nalbuphine (0.1 to $3 \mathrm{mg} / \mathrm{kg} /$ day) or (0.254 to $7.62 \mu \mathrm{mol} / \mathrm{kg} /$ day), butorphanol (0.01 to 0.3 $\mathrm{mg} / \mathrm{kg} /$ day) or $(0.0209$ to $0.628 \mu \mathrm{mol} / \mathrm{kg} /$ day $)$, and saline on cocaine and food self-administration were each studied for 40 sessions over 10 consecutive days. Cocaine (0.05 or $0.10 \mathrm{mg} / \mathrm{kg} / \mathrm{inj}$ ) and food (1-gm banana pellets) self-administration were maintained on a fixed ratio 4 (oariable ratio 16:S) schedule of reinforcement. Both nalbuphine and butorphanol reduced cocaine self-administration $(p<0.0001)$ but this effect was not selective since food self-administration also decreased in a dose-dependent manner $(p<0.0001)$. Nalbuphine administration (1 to $3 \mathrm{mg} / \mathrm{kg} /$ day) decreased cocaine injections to $40 \%$ to $60 \%$ below baseline $(p<0.01)$ and food pellets $30 \%$ to $68 \%$ below baseline $(p<0.01)$. Lower doses of nalbuphine $(0.10$ and $0.30 \mathrm{mg} / \mathrm{kg})$ did not change cocaine- or food-maintained responding significantly. All doses of butorphanol (0.01 to 0.3 $\mathrm{mg} / \mathrm{kg} /$ day) reduced cocaine injections to $16 \%$ to $58 \%$ below baseline $(p<0.01)$. Food self-administration decreased to $21 \%$ to $70 \%$ below baseline $(p<0.01)$ at butorphanol doses of 0.03 to $0.3 \mathrm{mg} / \mathrm{kg} /$ day). These data suggest that these opioid mixed agonist-antagonist analgesics may not be useful as pharmacotherapies for the treatment of cocaine abuse. [Neuropsychopharmacology 8:45-55, 1993]
KEY wORDs: Drug abuse; Cocaine; Butorphanol; Opioid mixed agonist-antagonist; Nalbuphine; Drug abuse treatment

There are no uniformly effective pharmacotherapies for cocaine abuse comparable to those available for the treatment of heroin abuse (Gawin and Ellinwood 1988; Jaffe 1990). Recent preclinical and clinical studies converge to suggest that an opioid mixed agonist-antago-

From the Alcohol and Drug Abuse Research Center, Harvard Medical School-McLean Hospital, 115 Mill Street, Belmont, Massachusetts 02178.

Address reprint requests to: Nancy K. Mello, Ph.D., Alcohol and Drug Abuse Research Center, Harvard Medical School-Mcl ean Hospital, 115 Mill Street, Belmont, Massachusetts 02178.

${ }^{1}$ Department of Psychiatry, The University of Vermont, Burlington, Vermont 05401,

Received October 22, 1991; revised January 15, 1992; accepted February 5, 1992. nist analgesic, buprenorphine, may be useful for the treatment of cocaine abuse by polydrug abusers (Mello and Mendelson 1992; Mendelson et al. 1991; Gastfriend et al. 1992). Previous studies have shown that buprenorphine significantly decreased heroin self-administration by heroin-dependent men (Mello and Mendelson 1980; Mello et al. 1982) and opiate self-administration by rhesus monkeys (Mello et al. 1983). The present report is one of a series of studies designed to evaluate the effects of opioid mixed agonist-antagonist analgesics on cocaine self-administration in a primate model of drug abuse (Mello et al. 1989, 1990, 1992).

We recently reported that buprenorphine selectively reduced cocaine self-administration by rhesus monkeys by $72 \%$ to $93 \%$ (Mello et al. 1989,1990 ) and cocaine self-administration remained significantly below saline treatment baseline levels for up to 120 days (Mello et al. 1992). Ongoing Phase I clinical trials indi- 
cate that buprenorphine also decreases cocaine abuse by men who are dually dependent on cocaine and heroin according to DSM-III-R criteria (Gastfriend et al. 1992; Mello and Mendelson 1992). Buprenorphine was more effective than methadone in reducing cocaine self-administration by heroin abusers (Kosten et al. 1989a, 1989b). The mechanics by which buprenorphine reduces cocaine self-administration are unclear, but may involve an interaction between dopaminergic and endogenous opioid peptide systems (Mello and Mendelson 1992; Mello et al. 1990) since the reinforcing and discriminative stimulus effects of cocaine are modulated by dopaminergic neural systems (for review see Dackis and Gold 1985; Fischman 1987; Johanson and Fischman 1989; Kuhar et al. 1988).

One goal of the present study was to determine if other opioid mixed agonist-antagonist analgesics also selectively reduce cocaine self-administration by rhesus monkeys. Nalbuphine and butorphanol were selected for study since both are currently approved by the Food and Drug Administration for use as analgesics and the pharmacology of these compounds has been studied extensively (Errick and Heel 1983; Pachter and Evans 1985; Schmidt et al. 1985). A second objective was to examine the extent to which differences in the putative opioid receptor affinities of these opioid mixed agonist-antagonists might influence their effects on cocaine self-administration.

Although nalbuphine, butorphanol, and buprenorphine were originally developed as analgesics, these opioid mixed agonist-antagonist drugs differ in chemical structure and opioid receptor affinities (for review see Jaffe and Martin 1990; Pachter and Evans 1985; Pircio et al. 1976; Schuster and Harris 1985). Nalbuphine and butorphanol are from the morphinan series (Schmidt et al. 1985; Woolverton and Schuster 1983) whereas buprenorphine is an oripavine derivative of thebaine (Lewis 1974; Lewis et al. 1983). Both nalbuphine and butorphanol have partial $\mu$ and $\kappa$ agonist activity (Dykstra 1990; Woods and Gmerek 1985) as well as $\mu$ antagonist opiate receptor activity (Jaffe and Martin 1990; Schmidt et al. 1985) but their relative receptor selectivity varies with the type of assay as well as the species studied (De Souza et al. 1988; Dykstra 1990). The analgesic effects of these drugs may involve more than one opioid receptor. Both $\mu$ and $\kappa$ agonist activity appear to contribute to their analgesic actions (De Souza et al. 1988; Goodman and Snyder 1982; Zimmerman et al. 1987), but butorphanol antagonizes $\kappa$ and $\mu$ agonists in some behavioral measures (Dykstra, 1990; Woods

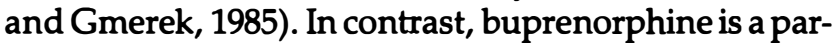
tial agonist at the $\mu$ opioid receptor and has $\kappa$ antagonist as well as $\mu$ antagonist activity in both physiologic and behavioral systems (Jaffe and Martin 1990; Mello et al. 1982; Leander 1987; Negus and Dykstra 1988; Negus et al. 1991; Richards and Sadee 1985).
The effects of nalbuphine and butorphanol on cocaine self-administration were examined with behavioral procedures identical to those previously used to evaluate buprenorphine's effects on cocaine selfadministration (Mello et al. 1989, 1990). Daily treatment with nalbuphine $(0.1$ to $3 \mathrm{mg} / \mathrm{kg} /$ day or 0.254 to 7.62 $\mu \mathrm{mol} / \mathrm{kg})$ or butorphanol $(0.01$ to $0.3 \mathrm{mg} / \mathrm{kg} /$ day or 0.0209 to $0.628 \mu \mathrm{mol} / \mathrm{kg}$ ) was compared with saline treatment. Saline and each dose of nalbuphine and butorphanol were studied for 10 days. Food-maintained responding was also studied to determine if any changes in cocaine self-administration during nalbuphine or butorphanol treatment were selective for drug-maintained responding, or reflected a generalized suppression of operant behavior. The importance of examining treatment drug effects on an alternative reinforcer, such as food, has been discussed elsewhere (Mello 1991, 1992).

\section{SUBJECTS AND METHODS}

\section{Animals}

Six rhesus monkeys (Macaca mulatta) (three females and three males) with a history of intravenous cocaine selfadministration were studied. At the beginning of this study, the nalbuphine group averaged 563 days of cocaine self-administration (range 126 to 995 days) and the butorphanol group averaged 611 days of cocaine self-administration (range 175 to 1,040 days). Monkeys weighed 7.3 to $12.2 \mathrm{~kg}$ and were maintained at ad libitum weight throughout the study. Monkeys were given two to four Purina Chow biscuits, multiple vitamins, fresh fruit (apple, orange, banana) and vegetables (lettuce, carrots) to supplement a banana pellet diet; water was continuously available. A 12-hour light/dark cycle was in effect (lights on from 7 A.M. to 7 P.M.) except that the experimental chamber was dark during food and drug self-administration sessions.

Monkeys were surgically implanted with doublelumen Silicone rubber catheters (I.D. 0.028 in, O.D. $0.080 \mathrm{in})$ to facilitate concurrent intravenous nalbuphine, butorphanol, or saline treatments and intravenous cocaine self-administration. Catheters were implanted in the jugular or femoral vein and exited in the midscapular region. All surgical procedures were performed under aseptic conditions and monkeys were anesthetized with ketamine $(25 \mathrm{mg} / \mathrm{kg}$ or 0.092 $\mathrm{mmol} / \mathrm{kg}, \mathrm{IM}$ ) and muscle relaxation was induced with diazepam $(0.3 \mathrm{mg} / \mathrm{kg}$, IM). After surgery, monkeys were given 200,000 units of Combiotic Dihydrostreptomycin and Penicillin G, intramuscularly every other day for a total of five injections. The intravenous catheter was protected by a tether system consisting of a custom-fitted nylon vest connected to a flexible stainless-steel cable and fluid swivel (Spaulding Medical 
Products, Arroyo Grande, CA). This flexible tether system permits monkeys to move freely within the cage.

Animal maintenance, surgical procedures, and research were conducted in accordance with the guidelines provided by the Committee on Laboratory Animal Resources. The facility is licensed by the U.S. Department of Agriculture and protocols were approved by the Institutional Animal Care and Use Committee. The health of the monkeys was periodically monit

gional Primate Research Center. Monkeys had visual and auditory contact with other monkeys throughout the study. Operant food and drug acquisition procedures provided an opportunity for environmental manipulation and enrichment (Line 1987; Line et al. 1989).

\section{Operant Behavioral Procedures and Apparatus}

Monkeys worked at an operant task for 1-gm banana pellets and for intravenous cocaine injections in a wellventilated chamber equipped with an operant panel, a pellet feeder, and a water dispenser. Cocaine injectionswere delivered by a syringe pump in a single pulse that dispensed $0.1 \mathrm{ml}$ of fluid over 0.9 seconds. The operation of the syringe pump (Model 981210, Harvard Apparatus, Inc., South Natick, MA) was audible to the monkey. Schedules of reinforcement were programmed by custom designed software and run on Apple Ile microcomputers.

Cocaine self-administration was studied at the dose that maintained the highest response rates during training in each monkey ( 0.05 or $0.10 \mathrm{mg} / \mathrm{kg} / \mathrm{inj})$. Cocaine doses lower and higher than the most reinforcing dose were not examined because nalbuphine and butorphanol each suppressed food-maintained responding across the dose range studied. These cocaine doses per injection were identical to those previously used in parallel studies of buprenorphine treatment (Mello et al. $1989,1990)$. Food (1-gm banana pellet) and cocaine selfadministration were maintained on a second-order schedule of reinforcement [fixed ratio 4 (FR 4), variable ratio (VR 16):S]. An average of 16 responses on a VR 16 produced a brief red or green stimulus light $(S+)$ and a drug injection or a food pellet was delivered only after a FR 4 of the VR 16 response requirements had been completed. Thus, each food pellet or drug injection required an average of 64 responses. Additional details of the apparatus have been published previously (Mello and Mendelson 1978).

The conditions of food and cocaine availability were each associated with a different colored stimulus light $(S+)$ projected on a translucent Plexiglas response key $(5 \mathrm{~cm}$ diameter) in the center of the operant panel. The stimulus lights $\left(S_{+}\right)$were extinguished during timeout periods when responses had no programmed consequence. When a food pellet or drug injection was de- livered, the appropriate colored stimulus light $(S+$ red or green) was illuminated for 1 second on the middle of 3 circles ( $2 \mathrm{~cm}$ diameter) located in a vertical column below the response key. These 1-second colored stimulus light flashes $(\mathrm{S}+)$ also signaled the completion of each successive component of the second-orderschedule response requirement.

Operant food and drug acquisition sessions were conducted 7 days each week. Each experimental day consisted of four food- and four-drug-availability sessions. Each food or drug session lasted for 1 hour or until 100 food pellets or 20 drug injections were delivered. Cocaine injections were limited to 80 per day to minimize the possibility of adverse drug effects. Food sessions began at 11:00 A.M., 3:00 P.M., 7:00 P.M., and 7:00 A.M. and drug sessions began 1 hour later at 12 noon, 4:00 P.M., 8:00 P.M., and 8:00 A.M.

\section{Butorphanol and Nalbuphine Administration}

The range of doses of butorphanol and nalbuphine studied were selected on the basis of their behavioral effects in previousstudies (Mello et al. 1988; Woods and Gmerek 1985; Young et al. 1984). Butorphanol is 3 to 30 times more potent than nalbuphine in studies designed to examine the reinforcing and discriminativestimulus properties of opioid mixed agonist-antagonist drugs (Mello et al. 1988; Woods and Gmerek 1985; Young et al. 1984). The results of preliminary studies of the effects of nalbuphine on cocaine suggested that $1 \mathrm{mg} / \mathrm{kg}$ of nalbuphine reduced rates of responding maintained by cocaine $(0.01 \mathrm{mg} / \mathrm{kg} / \mathrm{inj})$ from 1.8 to 0.4 responses per second (JH Woods, personal communication, 1990). Accordingly, we studied nalbuphine's effects on cocaine and food self-administration over a dose range of 0.1 to $3 \mathrm{mg} / \mathrm{kg} /$ day [0.254 to 7.62 $\mu \mathrm{mol} / \mathrm{kg} /$ day]. Butorphanol was studied over a dose range of 0.03 to $1 \mathrm{mg} / \mathrm{kg} /$ day [0.0209 to $0.628 \mu \mathrm{mol}$ $/ \mathrm{kg} /$ day]. The effects of nalbuphine and butorphanol were assessed in the same four subjects; nalbuphine was studied first and butorphanol was studied second. Two other monkeys received only nalbuphine $(\mathrm{CH} \mathrm{84})$ or only butorphanol (199C).

After 10 days of saline treatment, the effects of daily butorphanol treatment or daily nalbuphine treatment were studied for 10 days ( 40 sessions) at each dose. After completion of nalbuphine or butorphanol treatment, saline treatment was resumed and recovery of cocaineand food-maintained responding was observed over 10 to 30 days. All drug doses were given in an ascending order except for butorphanol in Monkey 1937.5 where the lowest dose tested $(0.003 \mathrm{mg} / \mathrm{kg} /$ day $)$ was studied last. Two monkeys (CH 84 and 1937.5) were not studied at the lowest dose of nalbuphine.

Butorphanol, nalbuphine, or an equal volume of saline control solution was administered once each day 
in a slow injection between 9:30 A.M. and 10:30 A.M. Each solution was gradually infused at a rate of $1 \mathrm{ml}$ of solution every 10 minutes and flushed through with sterile saline in a volume that exceeded the estimated catheter dead space. The duration of nalbuphine's analgesic action is 3 to 6 hours (Forbes et al. 1984; Schmidt et al. 1985). The plasma half-life of an analgesic dose of nalbuphine ( 10 to $20 \mathrm{mg}$ ) after intravenous administration in healthy volunteers has been estimated at between 1.9 and 3.7 hours (Aitkenhead et al. 1988); Jaillon et al. 1989; Lo et al. 1987). The pharmacokinetic profile of butorphanol is similar to that of nalbuphine. The plasma half-life of butorphanol is about 3 hours and it is effective as an analgesic for up to 4 hours (Jaffe and Martin 1990; Pachter and Evans 1985). In the present study, the time course of changes in the effects of butorphanol and nalbuphine on food and cocaine self-administration were measured across four successive food and drug sessions that spanned 0.5 to 22.5 hours after treatment drug administration.

Butorphanol and Nalbuphine Preparation. Butorphanol $\mathrm{HCl}$ was purchased as a $10 \mathrm{mg} / \mathrm{ml}$ commercially available solution (Torbugesic, Aveco Co., Inc., Fort Dodge, Iowa). Sterile stock solutions of 1 or $5 \mathrm{mg} / \mathrm{ml}$ were diluted from the commercially prepared solution by adding Sterile Saline for Injection, U.S.P. Nalbuphine $\mathrm{HCl}$ was donated by the DuPont Merck Pharmaceutical Corporation, Wilmington, Delaware. Nalbuphine was dissolved in saline to a concentration of 5,10 , or $20 \mathrm{mg} / \mathrm{ml}$. These stock solutions were filtersterilized using a 0.22 micron Millipore filter and stored in pyrogen-free vials. Stock solutions were diluted with sterile saline to deliver the appropriate milligram per kilogram dose in a volume of $5 \mathrm{ml}$. Solutions were checked daily to ensure that no precipitate had formed. Fresh stock solutions were prepared at least once a month.

Cocaine Preparation. Cocaine hydrochloride was obtained in crystalline form from National Institute on Drug Abuse. The purity was certified by Research Triangle to be greater than $98 \%$. Stock solutions of 50 $\mathrm{mg} / \mathrm{ml}$ were prepared by dissolving cocaine in Sterile Saline for Injection, U.S.P. The solution was filtersterilized using a 0.22 micron millipore filter and stored in sterile pyrogen-free vials. Doses were calculated on the basis of monkeys' weights so that a final dilution of the stock solution (with Sterile Saline for Injection, U.S.P.) resulted in a unit dose of 0.05 or $0.10 \mathrm{mg} / \mathrm{kg} / \mathrm{inj}$ in a volume of $0.1 \mathrm{ml} / \mathrm{inj}$.

\section{Data Analysis}

Butorphanol and nalbuphine effects on cocaine- and food-maintained responding were evaluated with oneway analysis of variance (ANOVA) for repeated mea- sures. If ANOVA showed a significant main effect, Dunnett's Multiple Comparison Procedure was used to compare the average number of cocaine injections or food pellets after butorphanol, nalbuphine, or saline treatment (Winer 1971). Probability levels of less than 0.05 and lower are reported as statistically significant. In some instances, data are expressed as the percent change from the saline treatment baseline to facilitate comparisons between animals.

\section{RESULTS}

\section{Nalbuphine's Effects on Cocaine and Food Self-Administration}

Baseline levels of cocaine self-administration averaged $58.8 \pm 2.1$ injections per day during 10 days of saline control treatment. The average dose of cocaine selfadministered was $3.91 \pm 0.49 \mathrm{mg} / \mathrm{kg} /$ day. Food selfadministration averaged $67.4 \pm 6.4$ pellets per day during saline control treatment.

As shown in Figure 1, the lowest dose of nalbuphine $(0.10 \mathrm{mg} / \mathrm{kg} /$ day $)$ had no effect on either cocaine or food self-administration. Cocaine self-administration decreased and food self-administration increased slightly at the next higher dose of nalbuphine $(0.30 \mathrm{mg} / \mathrm{kg} /$ day $)$. Both cocaine and food self-administration decreased significantly during treatment with 1 and $3 \mathrm{mg} / \mathrm{kg}$ of nalbuphine. Average cocaine self-administration decreased to $40 \%$ to $61 \%$ below baseline $(p<0.01)$. Food

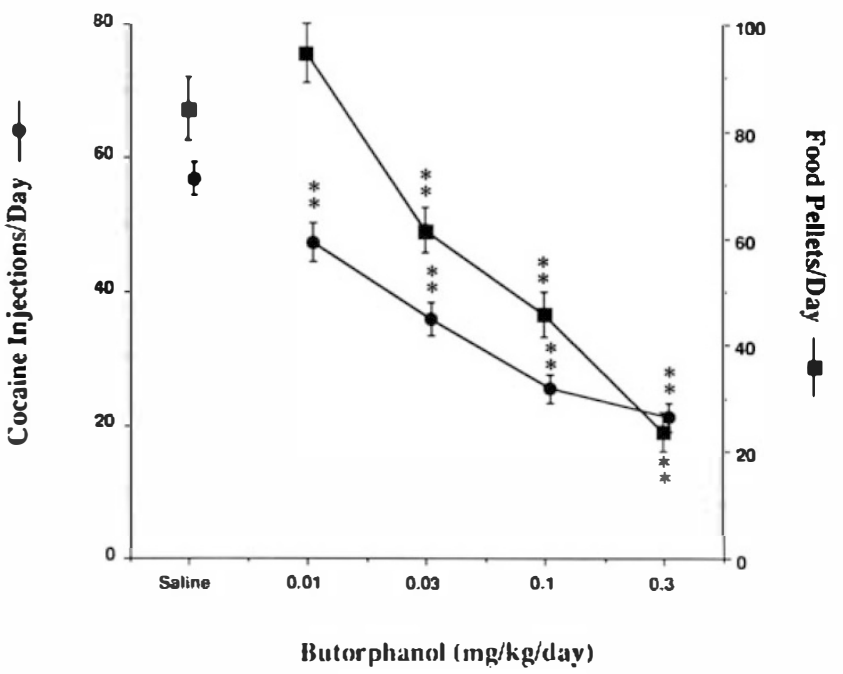

Figure 1. Effects of daily nalbuphine or saline treatment on cocaine and food self-administration. Saline treatment and each dose of nalbuphine were studied for 10 days. Each data point for cocaine (circles) and food (squares) is the average ( $\pm \mathrm{SE}$ ) of five subjects except for $0.1 \mathrm{mg} / \mathrm{kg}$ nalbuphine that is the average of three subjects. The statistical significance of each change from the saline treatment baseline is indicated by an asterisk $\left({ }^{\star} p<0.05 ;{ }^{\star *} p<0.01\right)$. 
self-administration decreased to $30 \%$ and $68 \%$ below baseline $(p<0.05-0.01)$.

Figure 2 shows the effects of nalbuphine and saline on cocaine and food self-administration by individual monkeys. Nalbuphine treatment significantly decreased cocaine self-administration in all five monkeys $(p<0.001)$. Food self-administration decreased significantly in three of five monkeys (CH84, 1937.5, 679C) $(p<0.001)$ (Fig. 2, rows 1 to 3 ). Food selfadministration did not change significantly from baseline in one monkey (606.5) and increased significantly $(p<0.001)$ in one monkey (371A) (Fig. 2, rows 4 and 5).

Monkeys differed in the degree of suppression of cocaine- and food-maintained responding by nalbuphine as well as in the time required to return to baseline levels after nalbuphine treatment ended. Monkey
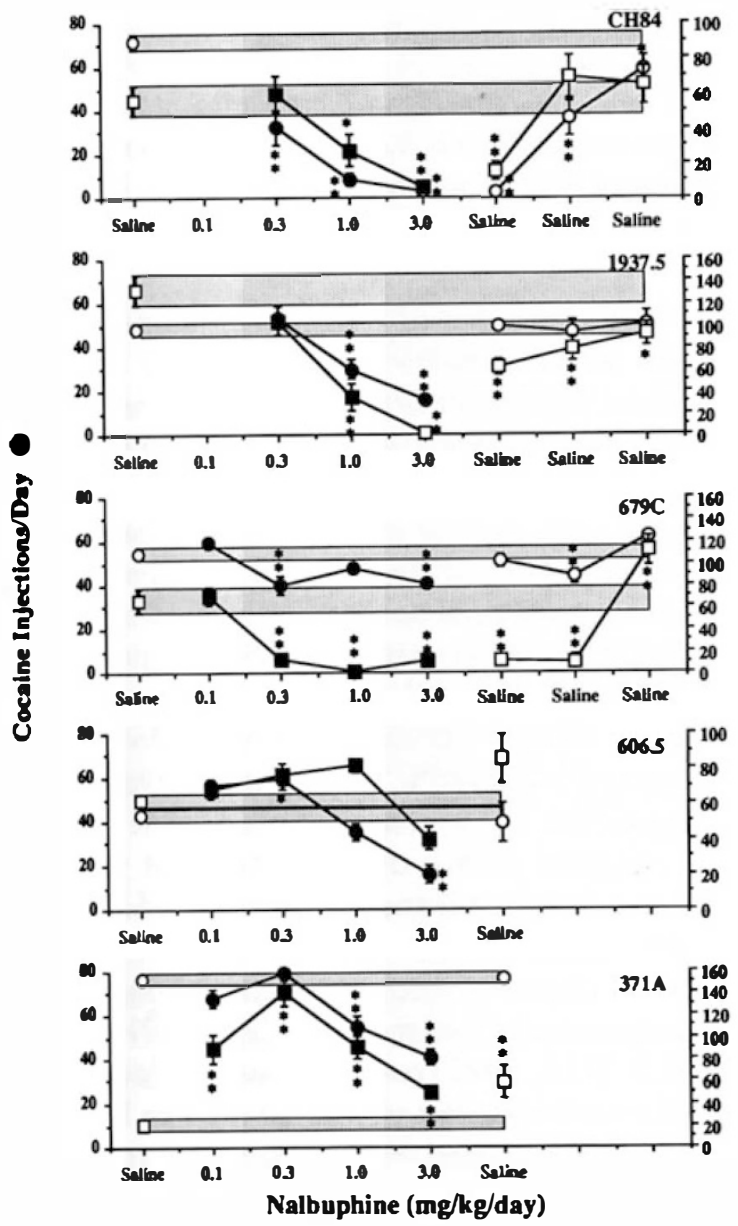

Figure 2. Effects of daily nalbuphine treatment or saline treatment on cocaine and food self-administration by individual monkeys. Each data point is the average ( $\pm \mathrm{SE}$ ) of 10 days of cocaine or food self-administration. The average number of cocaine injections self-administered per day is shown as circles. The average number of banana pellets selfadministered per day by each monkey is shown as squares. The statistical significance of each change from the saline treatment baseline is indicated by an asterisk ( $\left.{ }^{*} p<0.05 ;{ }^{*} p<0.01\right)$.
371A showed a significant increase in food-maintained responding throughout nalbuphine treatment $(p<0.01)$ and this was sustained during the 10-day postnalbuphine saline recovery period (Fig. 2, row 5). Cocainemaintained responding returned to baseline levels within 10 days after nalbuphine treatment ended in four of five monkeys (1937.5, 606.5, 679C, 371A) (Fig. 2, rows 2 to 5) but remained significantly below baseline for 30 days in Monkey $\mathrm{CH} 84$ (Fig. 2, row 1).

Food-maintained responding exceeded baseline levels during the first 10 days after nalbuphine treatment ended in Monkeys 606.5 and 371A (Fig. 2, rows 4 and 5). Food self-administration recovered within 20 days in Monkey $\mathrm{CH} 84$ and within 30 days in Monkey 679C (Fig. 2, rows 1 and 3). One monkey (1937.5) stabilized at a relatively high level of food intake $(92 \pm 10.4$ pellets per day) but did not recover to his prenalbuphine baseline level (Fig. 2, row 2).

\section{Time Course of Nalbuphine's Effects on Cocaine and Food Self-Administration}

Figure 3 shows the effects of saline and each dose of nalbuphine on cocaine- and food-maintained responding over consecutive sessions each day. During treatment with saline and $0.1 \mathrm{mg} / \mathrm{kg} /$ day nalbuphine, cocaine injections were evenly distributed across the four sessions. Higher doses of nalbuphine ( 1 to $3 \mathrm{mg} / \mathrm{kg} /$ day) decreased cocaine injections by $72 \%$ to $90 \%$ during the noon session that began 1.5 hours after nalbuphine. Cocaine injections remained $24 \%$ to $63 \%$ below baseline $(p<0.01)$ during the 4 P.M. and 8 P.M. sessions that began 5.5 and 9.5 hours after 1 and $3 \mathrm{mg} / \mathrm{kg} /$ day of nalbuphine. Cocaine-maintained responding tended to return toward baseline levels by the 8 A.M. session, 21.5 hours after nalbuphine treatment.

Food-maintained responding was also evenly distributed across the four daily sessions during saline treatment (Fig. 3). All doses of nalbuphine decreased food self-administration during the 11:00 A.M. session, 30 minutes after nalbuphine treatment. There was a compensatory increase in food self-administration to $70 \%$ to $91 \%(p<0.01)$ over baseline levels during the 3:00 P.M. and 7:00 P.M. sessions, 4.5 and 8.5 hours after nalbuphine ( 0.1 and $0.3 \mathrm{mg} / \mathrm{kg} /$ day). After treatment with the highest dose of nalbuphine $(3 \mathrm{mg} / \mathrm{kg} /$ day), food self-administration remained suppressed across all four sessions, 30 minutes to 20.5 hours postnalbuphine (Fig. 3).

\section{Butorphanol's Effects on Cocaine and Food Self-Administration}

Baseline levels of cocaine self-administration averaged $56.8 \pm 2.5$ injections per day during 10 days of saline control treatment. The average dose of cocaine self- 
Time Course of Nalbuphine's Effects
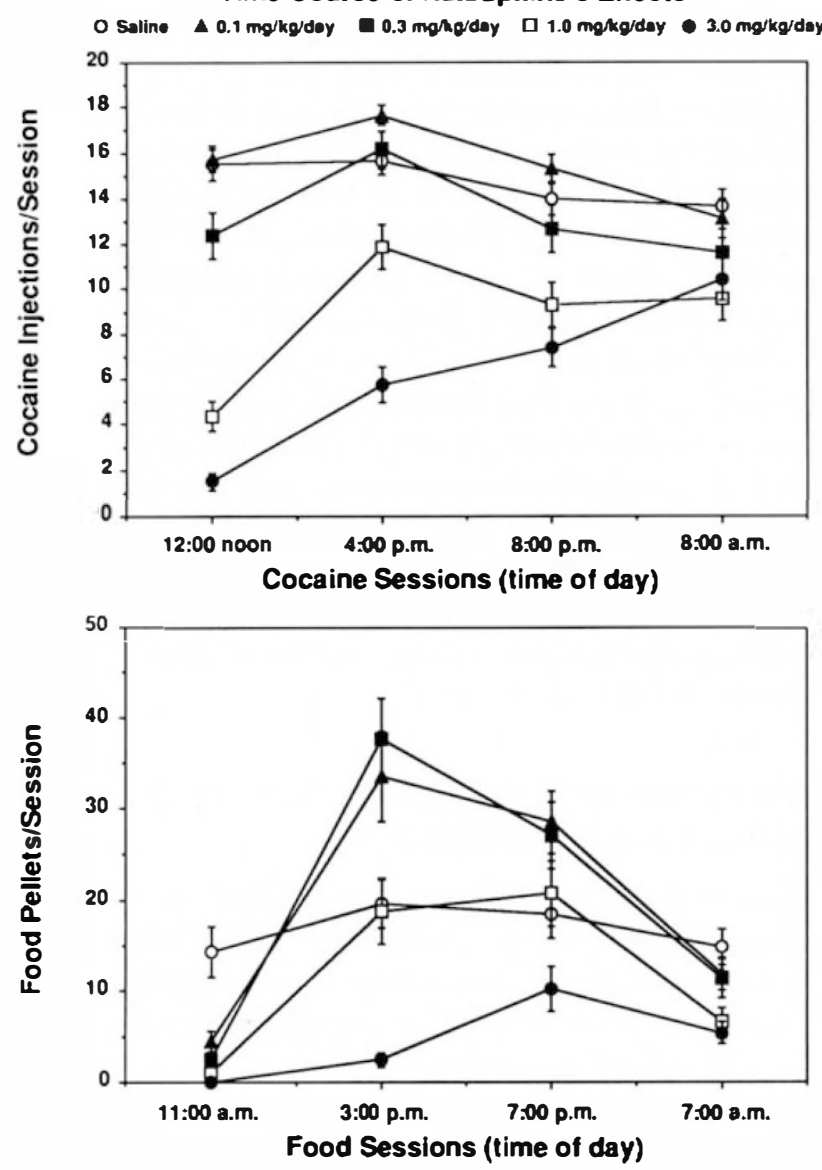

Figure 3. Time course of nalbuphine's effects on cocaine and food self-administration. Top Panel: The distribution of cocaine injections across four daily sessions that began 1.5, 5.5, 9.5, and 21.5 hours after daily treatment with saline or nalbuphine. Lower Panel: The distribution of food pellets across four daily sessions that began $0.5,4.5,8.5$, and 20.5 hours after daily treatment with saline or nalbuphine. Each data point is the average ( $\pm \mathrm{SE}$ ) of five subjects over 10 sessions except for 0.1 $\mathrm{mg} / \mathrm{kg}$ nalbuphine that is the average of three subjects. Average cocaine injections and food pellets per day are shown on the left ordinate and session times on the abscissa. Saline treatinent is shown as open circles. Nalbuphine treatment is shown as closed triangles $(0.1 \mathrm{mg} / \mathrm{kg} /$ day or $0.254 \mu \mathrm{mol} /$ $\mathrm{kg} /$ day); closed squares $(0.3 \mathrm{mg} / \mathrm{kg} /$ day or $0.762 \mu \mathrm{mol} / \mathrm{kg} /$ day); open squares ( $1 \mathrm{mg} / \mathrm{kg} /$ day or $2.54 \mu \mathrm{mol} / \mathrm{kg} /$ day); and closed circles $(3 \mathrm{mg} / \mathrm{kg} /$ day or $7.62 \mu \mathrm{mol} / \mathrm{kg} /$ day $)$.

administered was $4.06 \pm 0.91 \mathrm{mg} / \mathrm{kg} /$ day. Food selfadministration averaged $84.5 \pm 5.9$ pellets per day during saline control treatment. Butorphanol treatment resulted in a dose-dependent decrease in both cocaine and food self-administration as shown in Figure 4. Cocaine self-administration was decreased significantly $(p<0.01)$ by each dose of butorphanol and averaged $16 \%$ to $58 \%$ below baseline. Food self-administration was significantly decreased $(p<0.01)$ by butorphanol at doses of 0.03 to $0.3 \mathrm{mg} / \mathrm{kg} /$ day and averaged $21 \%$ to $70 \%$ below baseline levels.

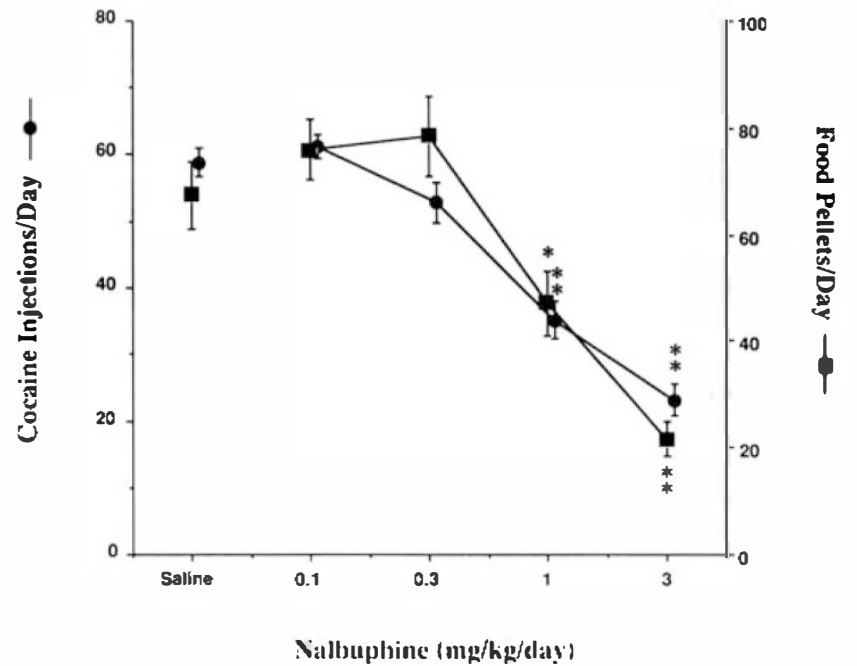

Figure 4. Effects of daily butorphanol or saline treatment on cocaine and food self-administration. Saline treatment and each dose of butorphanol were studied for 10 days. Each data point for cocaine (circles) and food (squares) is the average ( $\pm \mathrm{SE}$ ) of five subjects except for $0.3 \mathrm{mg} / \mathrm{kg}$ of butorphanol that is the average of four subjects. The statistical significance of each change from the saline treatment baseline is indicated by an asterisk $\left({ }^{*} p<0.05,{ }^{* *} p<0.01\right)$.

Individual profiles of cocaine self-administration and food self-administration during and following butorphanol treatment are shown in Figure 5. Four monkeys (1937.5, 679C, 606.5, 371A) showed dosedependent decreases in cocaine- and food-maintained responding (Fig. 5, rows 2 to 5). Cocaine self-administration was significantly reduced in Monkey $371 \mathrm{~A}$ $(p<0.01)$ at butorphanol doses of 0.01 to $0.10 \mathrm{mg} / \mathrm{kg} /$ day while food self-administration remained equivalent to control levels. At higher doses of butorphanol ( 0.1 and $0.3 \mathrm{mg} / \mathrm{kg}$ ), food self-administration was decreased in all monkeys by $34 \%$ to $88 \%$. These changes were statistically significant in seven instances. One monkey (1937.5) stopped eating during treatment with 0.10 $\mathrm{mg} / \mathrm{kg} /$ day butorphanol and was not studied at the 0.30 $\mathrm{mg} / \mathrm{kg} /$ day dose.

The time course of recovery of cocaine-maintained responding varied across monkeys (Fig. 5). Three monkeys $(606.5,371 \mathrm{~A}, 199 \mathrm{C})$ resumed baseline levels of cocaine self-administration within 10 days or less. One monkey $(679 \mathrm{C})$ required 20 days to return to baseline levels of cocaine self-administration (Fig. 5, row 3). No cocaine recovery data are available for Monkey 1937.5 because she was run on a low (and ineffective) dose of butorphanol $(0.003 \mathrm{mg} / \mathrm{kg} /$ day $)$ immediately before the postbutorphanol saline treatment period (Fig. 5, row 2).

Three monkeys (199C, 1937.5, 606.5) returned to saline control levels of food self-administration within 10 days after discontinuation of $0.3 \mathrm{mg} / \mathrm{kg} /$ day of butorphanol (Fig. 5, rows 1, 2, and 4). Food-maintained responding recovered more slowly than cocaine- 


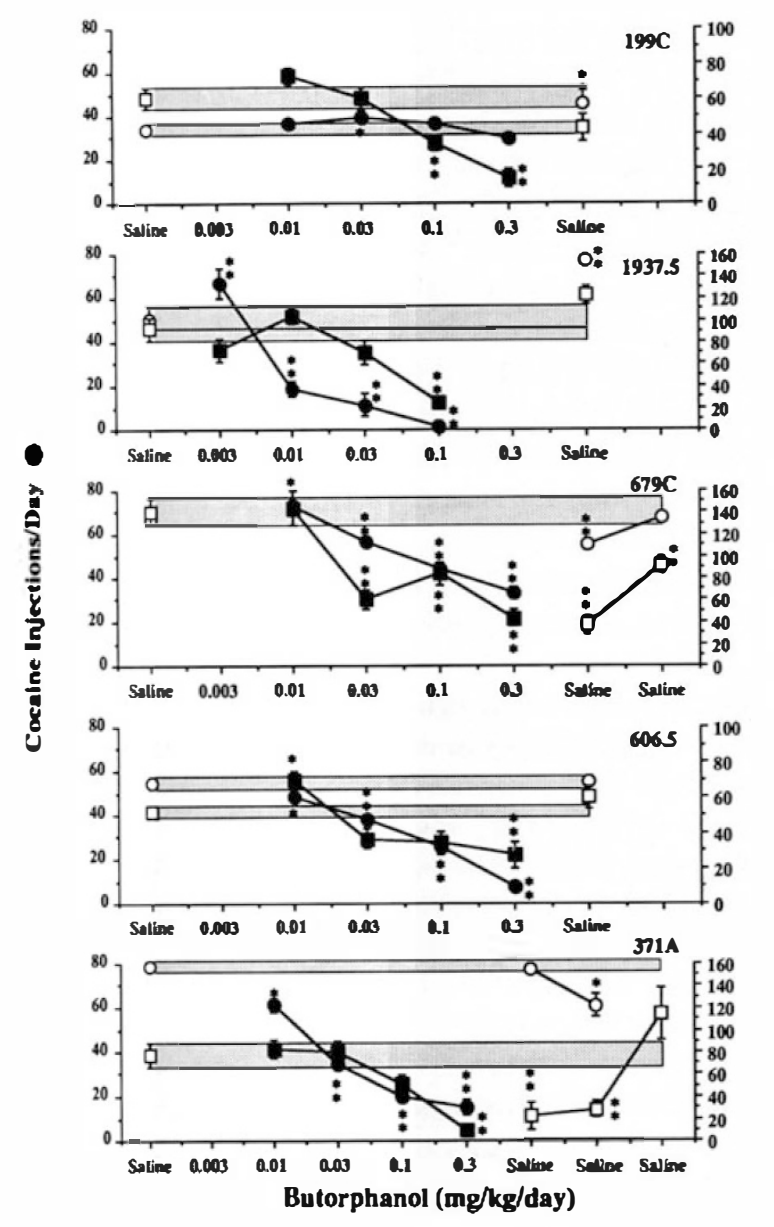

Figure 5. Effects of daily butorphanol treatment or saline treatment on cocaine and food self-administration by individual monkeys. Each data point is the average $( \pm S E)$ of 10 days of cocaine or food self-administration. The average number of cocaine injections self-administered per day is shown as circles. The average number of banana pellets self-administered per day by each monkey is shown as squares. The statistical significance of each change from the saline treatment baseline is indicated by an asterisk $\left({ }^{*} p<0.05 ;{ }^{* *} p<0.01\right)$.

maintained responding after butorphanol treatment in two monkeys (679C, 371A) (Fig. 5, rows 3 and 5). Monkey $371 \mathrm{~A}$ dislodged her catheter 21 days after butorphanol treatment ended.

\section{Time Course of Butorphanol's Effects on Cocaine and Food Self-Administration}

Figure 6 shows the effects of each dose of butorphanol on cocaine self-administration over consecutive drug availability sessions 1.5 to 21.5 hours after butorphanol treatment. Figure 6 shows butorphanol's effects on food self-administration, 30 minutes to 20.5 hours after butorphanol treatment.

Cocaine injections were evenly distributed across the four daily sessions during saline treatment (Fig. 6).
Time Course of Butorphanol's Effects
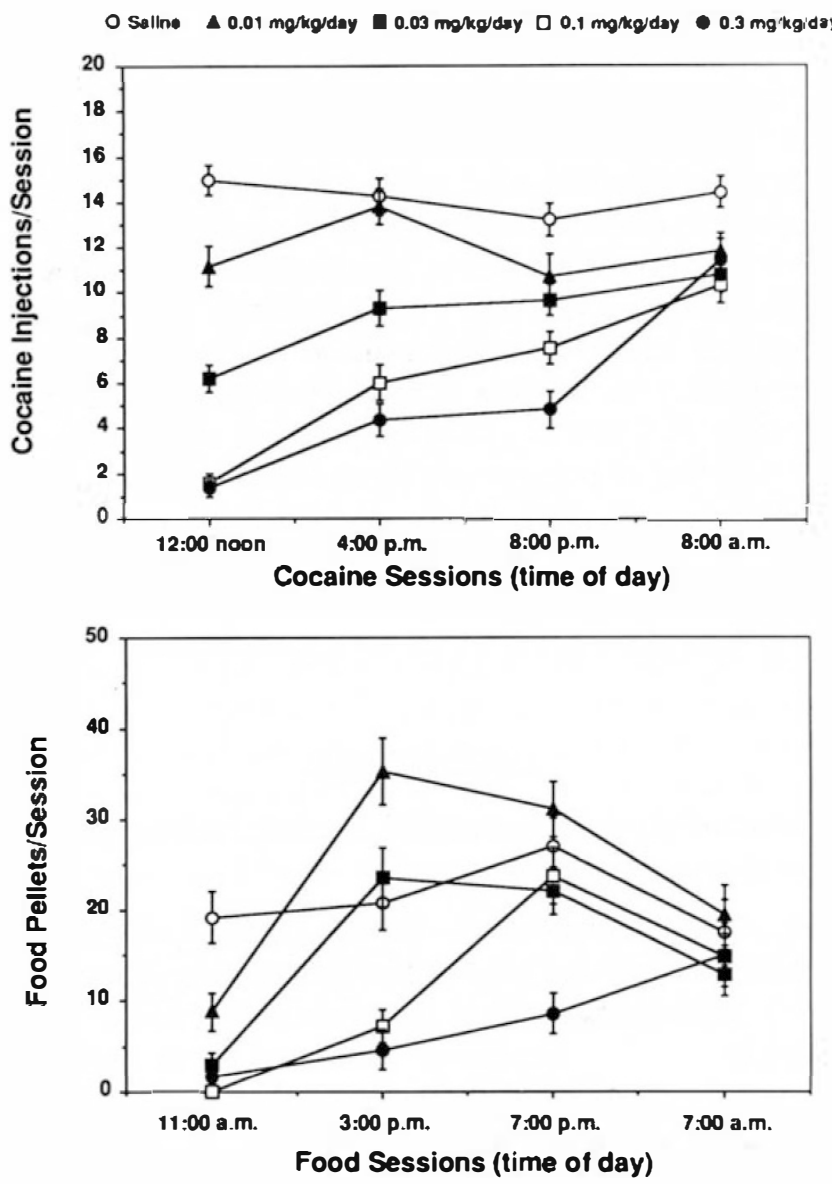

Figure 6. Time-course of butorphanol's effects on cocaine self-administration. Top Panel: The distribution of cocaine injections across four daily sessions that began 1.5, 5.5, 9.5, and 21.5 hours after daily treatment with saline or butorphanol. Lower Panel: The distribution of food pellets across four daily sessions that began $0.5,4.5,8.5$, and 20.5 hours after daily treatment with saline or butorphanol. Each data point is the average $( \pm \mathrm{SE}$ ) of five monkeys over 10 daily sessions except for $0.3 \mathrm{mg} / \mathrm{kg}$ butorphanol that is the average of four subjects. Average cocaine injections or food pellets per day are shown on the left ordinate and session times are shown on the abscissa. Saline treatment is shown as open circles. Butorphanol treatment is shown as closed triangles $(0.01 \mathrm{mg} / \mathrm{kg} /$ day or 0.0209 $\mu \mathrm{mol} / \mathrm{kg} /$ day $)$; closed squares $(0.03 \mathrm{mg} / \mathrm{kg} /$ day or $0.0628 \mu \mathrm{mol} /$ $\mathrm{kg} /$ day); open squares $(0.10 \mathrm{mg} / \mathrm{kg} /$ day or $0.209 \mu \mathrm{mol} / \mathrm{kg} /$ day $)$; and closed circles $(0.3 \mathrm{mg} / \mathrm{kg} /$ day or $0.628 \mu \mathrm{mol} / \mathrm{kg} /$ day $)$.

Butorphanol produced dose-related decreases in cocaine self-administration during the 12:00 noon session. These decreases were sustained during the 4:00 P.M. and 8:00 P.M. sessions after 0.10 and $0.30 \mathrm{mg} / \mathrm{kg} /$ day of butorphanol. The degree of suppression of cocaine maintained-responding during the 8:00 A.M. session was equivalent after all doses of butorphanol (Fig. 6). After 0.1 and $0.3 \mathrm{mg} / \mathrm{kg} /$ day of butorphanol, cocaine self-administration during the 8:00 A.M. session was 
significantly higher than during the noon session $(p<$ 0.01).

Food self-administration was reduced by all doses of butorphanol to $53 \%$ to $99 \%$ below baseline during the 11:00 A.M. sessions (Fig. 6). By 3:00 P.M., food selfadministration increased above baseline levels after low doses of butorphanol ( 0.01 and $0.03 \mathrm{mg} / \mathrm{kg} /$ day) but remained $65 \%$ to $77 \%$ below baseline after higher doses of butorphanol (0.1 and $0.3 \mathrm{mg} / \mathrm{kg} /$ day). By 7:00 P.M. food self-administration returned to baseline levels except after the highest dose of butorphanol $(0.3 \mathrm{mg} /$ $\mathrm{kg} /$ day). By 7:00 A.M., food-maintained responding after all doses of butorphanol was similar to saline control treatment levels. Food-maintained responding after 0.1 and $0.3 \mathrm{mg} / \mathrm{kg} /$ day of butorphanol was significantly higher during the 7:00 A.M. sessions $(p<$ 0.01 ) than during the 11:00 A.M. sessions (Fig. 6).

\section{DISCUSSION}

\section{Cocaine Self-Administration During Nalbuphine and Butorphanol Treatment}

This is the first report of the effects of these opioid mixed agonist-antagonist analgesics on concurrent cocaine and food self-administration by rhesus monkeys. Nalbuphine and butorphanol treatment were each associated with significant $(P<0.0001)$ dose-dependent decreases in cocaine self-administration. The highest dose of nalbuphine ( $3 \mathrm{mg} / \mathrm{kg} / \mathrm{inj})$ and butorphanol ( 0.3 $\mathrm{mg} / \mathrm{kg} / \mathrm{inj}$ ) reduced the number of cocaine injections from equivalent baseline levels $(58.7 \pm 2.1$ and $56.8 \pm$ $2.5 \mathrm{inj} / \mathrm{day})$ to similar nadirs $(23 \pm 2.4$ and $21.18 \pm 2.14$ inj/day) (Figs. 1 and 4). The average daily dose of cocaine self-administered decreased from baseline levels of $3.91 \pm 0.49$ and $4.06 \pm 0.91 \mathrm{mg} / \mathrm{kg} /$ day to $1.73 \pm 1.5$ and $1.58 \pm 1.2 \mathrm{mg} / \mathrm{kg} /$ day. Individual patterns of cocaine self-administration during nalbuphine and butorphanol treatment (Figs. 2 and 5) were consistent with the group average data (Figs. 1 and 4). But two monkeys were more sensitive to butorphanol's effects on cocaine-maintained responding than to nalbuphine (Figs. 2 and 5, rows 3 and 4).

It is noteworthy that the effects of each dose of nalbuphine and butorphanol were relatively constant across each 10-day period of observation (Figs. 1 and 4). Consequently, we conclude that tolerance to the effects of nalbuphine and butorphanol on cocaine selfadministration over 40 days of treatment did not occur. Cocaine self-administration rapidly returned to baseline levels after cessation of nalbuphine (Fig. 2) or butorphanol treatment (Fig. 5). This pattern of recovery suggests that nalbuphine or butorphanol treatment, and not uncontrolled variables, accounted for the decreases in cocaine self-administration observed.

The maximum effects of each treatment drug oc- curred during the first, second, and third daily cocaine session, 1.5, 5.5, and 9.5 hours after the end of the nalbuphine or butorphanol infusion (Figs. 3 and 6). Daily cocaine self-administration occurred primarily in the 8:00 A.M. session, 21.5 hours after nalbuphine or butorphanol administration. The relatively short duration of action of these compounds would limit their usefulness as pharmacotherapies for cocaine abuse.

Nalbuphine's suppressive effects on cocaine selfadministration are consistent with a previous observation that nalbuphine $(1 \mathrm{mg} / \mathrm{kg})$ reduced cocaine-maintained response rates in rhesus monkeys ( $\mathrm{JH}$ Woods, personal communication, 1990). However, nalbuphine effects on food-maintained responding were not examined in that study $\mathrm{JH}$ Woods, personal communication, 1990).

Butorphanol was approximately 10 times more potent than nalbuphine in reducing cocaine self-administration (compare Figs. 1 and 4). These data are in accordance with previous reports that the reinforcing and discriminative-stimulus properties of butorphanol are 3 to 30 times more potent than nalbuphine (Mello et al. 1988; Woods and Gmerek 1985; Young 1991; Young et al. 1984).

\section{Food Self-Administration During Nalbuphine and Butorphanol Treatment}

A dose-dependent decrease in food self-administration $(p<0.001)$ also occurred during treatment with both nalbuphine and butorphanol (Figs. 1 and 4). Butorphanol reduced food-maintained responding in each individual monkey (Fig. 5) whereas some doses of nalbuphine were associated with increased food selfadministration (Fig. 2, rows 3 and 4). In one instance, food self-administration during the prenalbuphine saline treatment was lower than that measured in any other monkey and remained lower during the postnalbuphine saline treatment period (Fig. 2, row 5). Recovery of food-maintained responding tended to be more rapid after termination of butorphanol treatment than after cessation of nalbuphine treatment (Figs. 2 and 5); yet during nalbuphine and butorphanol treatment, the pattern of recovery of food self-administration across sessions within a day was quite similar for the two drugs (Figs. 3 and 6).

These findings confirm and extend previous reports that butorphanol and nalbuphine reduce rates of foodmaintained responding in the absence of cocaine (Harris 1980; Lukas et al. 1986). Butorphanol and nalbuphine suppressed food-maintained responding in baboons at doses similar to those in the present study but ad libitum food consumption was either not affected or was slightly elevated during 15 daily sessions of butorphanol or nalbuphine self-administration (Lukas et al. 1986). It was possible, although difficult, to antagonize the 
rate-suppressant effects of butorphanol with naloxone, suggesting that this effect may not be solely linked with a single opiate receptor (Harris 1980). The observed decrease in food self-administration following treatment with these $\kappa$ agonists is not consistent with reports that $\mathrm{K}$ agonists induce feeding (Billington et al. 1990; Jackson and Cooper 1986; Levine and Morley 1983; Lynch etal. 1985; Morley et al. 1982, 1983; Poggioli et al. 1986). But it is important to distinguish between feeding, a biologically based consumatory behavior, and schedulecontrolled behavior where food is a reinforcer (Lukas et al. 1986).

\section{Implications for Treatment of Cocaine Abuse with Nalbuphine and Butorphanol}

Since nalbuphine and butorphanol treatment reduced both cocaine- and food-maintained responding, their effects were not selective for cocaine. Rather, the parallel dose-dependent decreases in cocaine and food selfadministration (Figs. 1 and 4) suggest that these drugs exerted a general suppressant effect on operant behavior. These data contrast sharply with the effects of another opioid mixed agonist-antagonist, buprenorphine, on cocaine and food self-administration. We previously reported that buprenorphine selectively reduced cocaine self-administration by three monkeys (CH84, 679C, 199C) that were also subjects in the present study (Figs. 2 and 5) (Mello et al. 1990). Buprenorphine reduced cocaine self-administration by $72 \%$ to $93 \%$ and although food self-administration was initially suppressed, this effect was not dose dependent and tolerance developed to buprenorphine's suppressive effects on food intake (Mello et al. 1989, 1990, 1992). Since cocaine self-administration remained suppressed while food self-administration returned to baseline levels, we concluded that buprenorphine had a selective effect on cocaine self-administration (Mello et al. 1989, 1990, 1992). Acute buprenorphine administration usually reduces food self-administration (Dykstra 1983; Leander 1983; Lukas et al. 1986; Mello et al. 1985) but tolerance develops during chronic administration (Lukas et al. 1988; Mello et al. 1981, 1985, 1992).

The difference in the effects of these three opioid mixed agonist-antagonist analgesics on cocaine and food self-administration presumably reflects differences in their respective opioid receptor affinities. Each drug has both $\mu$ and $\kappa$ opioid receptor activity, but their profiles of agonist and antagonist activity are very complex and vary with the endpoint measure (De Souza et al. 1988; Dykstra 1990). Nalbuphine, butorphanol, and buprenorphine have partial $\mu$ agonist as well as $\mu$ antagonist actions under some conditions. Nalbuphine and butorphanol each have $\kappa$ agonist activity (Jaffe and Martin 1990; Schmidt et al. 1985), whereas buprenorphine has $\mathrm{K}$ antagonist activity (Jaffe and Martin 1990;
Negus and Dykstra 1988; Negus et al. 1991; Richards and Sadee 1985). The extent to which buprenorphine's $\kappa$ antagonist properties may be a critical factor in its selective effects on cocaine self-administration remains to be determined (see Mello and Mendelson 1992) since butorphanol and nalbuphine also have partial $\kappa$ antagonist effects in some paradigms (Dykstra 1990). Butorphanol was more potent than nalbuphine as a $k$ antagonist in a shock-titration behavioral paradigm and butorphanol antagonized the effects of both $\mu$ and $\kappa$ agonists on shock-maintained behavior (Dykstra 1990). Although butorphanol's effects on cocaine self-administration were not selective in the present study (Figs. 4 and 5), it reduced cocaine-maintained responding in a monotonic dose-dependent manner (Fig. 5), whereas nalbuphine's effects were less consistent across individuals (Fig. 2).

We conclude that nalbuphine and butorphanol, across the dose range studied, are unlikely to be useful as pharmacotherapies for the treatment of cocaine abuse. The concurrent and sustained reductions in food-maintained behavior and the short duration of action of nalbuphine and butorphanol, compared to buprenorphine (Jasinski et al. 1978), furthersuggest that these opioid mixed agonist-antagonist analgesics may have limited utility for cocaine abuse treatment.

\section{ACKNOWLEDGMENTS}

This research was supported in part by Grants DA 02519, DA 04059, DA 00101, DA 00064, and DA 00115 from the National Institute on Drug Abuse, ADAMHA and Grant RR 05484 awarded to the McLean Hospital by the Biomedical Research Support Program, Division of Research Resources, National Institutes of Health. We thank the Du Pont Merck Pharmaceutical Company for a generous gift of nalbuphine hydrochloride. We thank Nicolas Diaz-Migoyo and Michelle Kaviani for excellent technical assistance in data collection. We are grateful to Dr. James H. Woods for sharing his preliminary findings on nalbuphine's effects on cocaine self-administration with us. We thank Dr. Woods and Dr. Leonard Cook for their consultation about these data. Preliminary data were presented at the Annual Meeting of the Committee on Problems of Drug Dependence in 1991.

\section{REFERENCES}

Aitkenhead AR, Lin ES, Achola KJ (1988): The pharmacokinetics of oral and intravenous nalbuphine in healthy volunteers. Br J Clin Pharmacol 25:264-268

Billington CJ, Herman BH, Bartness TJ, Levine AS, Morley JE (1990): Effects of the opiate antagonists diprenorphine and naloxone and of selected opiate agonists on feeding behavior in guinea pigs. Life Sci 46:147-154

Dackis CA, Gold MS (1985): Pharmacological approaches to cocaine addiction. J Subst Abuse Treat 2:139-145

De Souza EB, Schmidt WK, Kuhar MJ (1988): Nalbuphine: An autoradiographic opioid receptor binding profile in 
the central nervous system of an agonist/antagonist analgesic. J Pharmacol Exp Ther 244:391-402

Dykstra L (1990): Butorphanol, levallorphan, nalbuphine and nalorphine as antagonists in the squirrel monkey. J Pharmacol Exp Ther 254:245-252

Dykstra LA (1983): Behavioral effects of buprenorphine and diprenorphine under a multiple schedule of food presentation in squirrel monkeys. J Pharmacol Exp Ther 226:317-323

Errick JK, Heel RC (1983): Nalbuphine: A preliminary review of its pharmacological properties and therapeutic efficacy. Drugs 26:191-211

Fischman MW (1987): Cocaine and the amphetamines. In Meltzer HY (ed), Psychopharmacology, The Third Generation of Progress. New York, Raven Press, pp 1543-1553

Forbes JA, Kolodny AL, Chachich BM (1984): Nalbuphine, acetaminophen and their combination in postoperative pain. Clin Pharmacol Ther 35:843-851

Gastfriend DR, Mendelson JH, Mello NK, Teoh SK (1992): Preliminary results of an open trial of buprenorphine in the outpatient treatment of combined heroin and cocaine dependence. NIDA Res Monogr 119:461

Gawin FH, Ellinwood EH (1988): Cocaine and other stimulants, actions, abuse, and treatment. $\mathrm{N}$ Engl J Med 318:1173-1182

Goodman RR, Snyder SH (1982): Autoradiographic localization of kappa opiate receptors to deep layers of the cerebral cortex may explain unique sedative and analgesic effects. Life Sci 31:1291-1294

Harris RA (1980): Interactions between narcotic agonists, partial agonists and antagonists evaluated by schedulecontrolled behavior. J Pharmacol Exp Ther 213:497-503

Jackson A, Cooper SJ (1986): An observational analysis of the effect of the selective kappa opioid agonist, U-50,488H, on feeding and related behaviours in the rat. Psychopharmacology 90:217-221

Jaffe JH (1990): Drug addiction and drug abuse. In Gilman AG, Rall TW, Nies AS, Taylor P (eds). The Pharmacological Basis of Therapeutics. 8th ed. New York, Pergamon Press, pp 522-573

Jaffe JH, Martin WR (1990): Opioid analgesics and antagonists. In Gilman AG, Rall TW, Nies AS, Taylor P (eds), The Pharmacological Basis of Therapeutics. 8th ed. New York, Pergamon Press, pp 485-521

Jaillon P, Gardin ME, Lecocq B, Richard MO, Mcignan S, Blondel Y, Grippat JC, Bergnieres J, Vergnoux O (1989): Pharmacokinetics of nalbuphine in infants, young healthy volunteers, and elderly patients. Clin Pharmacol Ther 46:226-233

Jasinski DR, Pevnick JS, Griffith JD (1978): Human pharmacology and abuse potential of the analgesic buprenorphine. Arch Gen Psychiatry 35:601-616

Johanson C-E, Fischman MW (1989): The pharmacology of cocaine related to its abuse. Pharmacol Rev 41:3-52

Kosten TR, Kleber HD, Morgan C (1989a): Role of opioid antagonists in treating intravenous cocaine abuse. Life Sci 44:887-892

Kosten TR, Kleber HD, Morgan C (1989b): Treatment of cocaine abuse with buprenorphine. Biol Psychiatry 26: $637-639$
Kuhar MJ, Ritz MC, Sharkey J (1988): Cocaine receptors on dopamine transporters mediate cocaine reinforced behavior. NIDA Res Monogr 88:14-22

Leander JD (1983): Opioid agonist and antagonist behavioral effects of buprenorphine. Br J Pharmacol 78:607-615

Leander JD (1987): Buprenorphine has potent kappa opioid receptor antagonist activity. Neuropharmacology 26: 1445-1447

Levine AS, Morley JE (1983): Butorphanol tartrate induces feeding in rats. Life Sci 32:781-785

Lewis JW (1974): Ring C-bridged derivatives of thebaine and oripavine. In Braude MC, Harris LS, May EL, Smith JP, Villarreal JE (eds), Narcotic Antagonists. Advances in Biochemical Psychopharmacology. New York, Raven Press, pp 123-136

Lewis JW, Rance MJ, Sanger DJ (1983): The pharmacology and abuse potential of buprenorphine: $A$ new antagonist analgesic. In Mello NK (ed), Advances in Substance Abuse: Behavioral and Biological Research, Vol. III. Greenwich, CT, JAI Press, pp 103-154

Line SW (1987): Environmental enrichment for laboratory primates. JAVMA 90:854-859

Line SW, Markowitz H, Morgan KN, Strong S (1989): Evaluation of attempts to enrich the environment of singlecaged non-human primates. In Driscoll JW (ed), Animal Care and Use in Behavioral Research: Regulations, Issues and Applications. Beltsville, MD, National Agricultural Library, pp 103-117

Lo MW, Schary WL, Whitney CCJ (1987): The disposition and bioavailability of intravenous and oral nalbuphine in healthy volunteers. J Clin Pharmacol 27:866-873

Lukas SE, Brady JV, Griffiths RR (1986): Comparison of opioid self-injection and disruption of schedule-controlled performance in the baboon. J Pharmacol Exp Ther 238:924-931

Lukas SE, Mello NK, Bree MP, Mendelson JH (1988): Differential tolerance development to buprenorphine-, diprenorphine-, and heroin-induced disruption of food-maintained responding in macaque monkeys. Pharmacol Biochem Behav 30:977-982

Lynch WC, Watt J, Krall S, Paden CM (1985): Autoradiographic localization of kappa opiate receptors in CNS taste and feeding areas. Pharmacol Biochem Behav 22:699-705

Mello NK (1991): Pre-clinical evaluation of the effects of buprenorphine, naltrexone and desipramine on cocaine self-administration. NIDA Res Monogr 105:189-195

Mello NK (1992): Behavioral strategies for the evaluation of new pharmacotherapies for drug abuse treatment. NIDA Res Monogr 119:150-154

Mello NK, Mendelson JH (1978): Self-administration of an enkephalin analog by rhesus monkey. Pharmacol Biochem Behav 9:579-586

Mello NK, Mendelson JH (1980): Buprenorphine suppresses heroin use by heroin addicts. Science 27:657-659

Mello NK, Mendelson JH (in press): Buprenorphine's effects on cocaine and heroin abuse. In Korenman S, Barchas J (eds), The Biological Basis of Substance Abuse. New York, Oxford Press

Mello NK, Mendelson JH, Kuehnle JC, Sellers ML (1981): Operant analysis of human heroin self-administration 
and the effects of naltrexone. J Pharmacol Exp Ther 216:45-54

MelloNK, Mendelson JH, Kuehnle JC (1982): Buprenorphine effects on human heroin self-administration. J Pharmacol Exp Ther 223:30-39

Mello NK, Bree MP, Mendelson JH (1983): Comparison of buprenorphine and methadone effects on opiate selfadministration in primates. J Pharmacol Exp Ther 225: 378-386

Mello NK, Bree MP, Lukas SE, Mendelson JH (1985): Buprenorphine effects on food-maintained responding in macaque monkeys. Pharmacol Biochem Behav 23: 1037-1044

Mello NK, Lukas SE, Bree MP, Mendelson JH (1988): Relative reinforcing properties of opioid mixed agonistantagonist drugs. NIDA Res Monogr 90:43

Mello NK, Mendelson JH, Bree MP, Lukas SE (1989): Buprenorphine suppresses cocaine self-administration by rhesus monkeys. Science 145:859-862

Mello NK, Mendelson JH, Bree MP, Lukas SE (1990): Buprenorphine and naltrexone effects on cocaine selfadministration by rhesus monkeys. J Pharmacol Exp Ther 254:926-939

Mello NK, Lukas SE, Kamien JB, Mendelson JH, Drieze J (1992): The effects of chronic buprenorphine treatment on cocaine and food self-administration by rhesus monkey. J Pharmacol Exper Ther 260:1185-1193

Mendelson JH, Mello NK, Teoh SK, Kuehnle J, Sintavanarong P, Dooley-Coufos K (1991): Buprenorphine treatment for concurrent heroin and cocaine dependence, Phase I Study. NIDA Res Monogr 105:196-202

Morley JE, Levine AS, Grace M, Kneip J (1982): An investigation of the role of kappa opiate receptor agonists in the initiation of feeding. Life Sci 31:2617-2626

Morley JE, Levine AS, Kneip J, Grace M, Billington CJ (1983): The effect of peripherally administered satiety substances on feeding induced by butorphanol tartrate. Pharmacol Biochem Behav 19:577-582

Negus SS, Dykstra LA (1988): Kappa antagonist properties of buprenorphine in the shock titration procedure. Eur J Pharmacol 56:77-86
Negus SS, Picker MJ, Dykstra LA (1991): Interactions between the discriminative stimulus effects of mu and kappa opioids in the squirrel monkey. J Pharmacol Exp Ther 256: 149-158

Pachter IJ, Evans RP (1985): Butorphanol. Drug Alcohol Depend 14:325-338

Pircio AW, Gylys JA, Cavanagh RL, Buyniski JP, Bierwagen MD (1976): The pharmacology of butorphanol, a 3,14dihydroxymorphinan narcotic antagonist analgesic. Arch Int Pharmacodyn 220:231-257

Poggioli R, Veroni AV, Bertolini A (1986): ACTH-(1-24) and alpha-MSH antagonize feeding behavior stimulated by kappa opiate agonists. Peptides 7:843-848

Richards ML, Sadee (1985): Buprenorphine is an antagonist at the kappa opioid receptor. Pharm Res 2:178-181

Schmidt WK, Tam SW, Shotzberger GS, Smith JDH, Clark R, Vernier VG (1985): Nalbuphine. Drug Alcohol Depend 14:339-362

Schuster CR, Harris LS (1985): Mixed agonist-antagonist analgesics. Drug Alcohol Depend 14:221-418

Winer BJ (1971): Statistical Principles in Experimental Design. New York, McGraw-Hill

Woods JH, Gmerek DE (1985): Substitution and primary dependence studies in animals. Drug Alcohol Depend 14:233-247

Woolverton W, Schuster CR (1983): Behavioral and pharmacological aspects of opioid dependence: Mixed agonistantagonists. Pharmacol Rev 35:33-52

Young AM (1991): Discriminative stimulus profiles of psychoactive drugs. In Mello NK (ed), Advances in Substance Abuse: Behavioral and Biological Research, Vol. IV. London, Jessica Kingsley Ltd, pp 139-203

Young AM, Stephens KR, Hein DW, Woods JH (1984): Reinforcing and discriminative stimulus properties of mixed agonist-antagonist opioids. J Pharmacol Exp Ther 229: 118-125

Zimmerman DM, Leander JD, ReelJK, Hynes MD (1987): Use of $\beta$-Funaltrexamine to determine mu opioid receptor involvement in the analgesic activity of various opioid ligands. J Pharmacol Exp Ther 241:374-378 